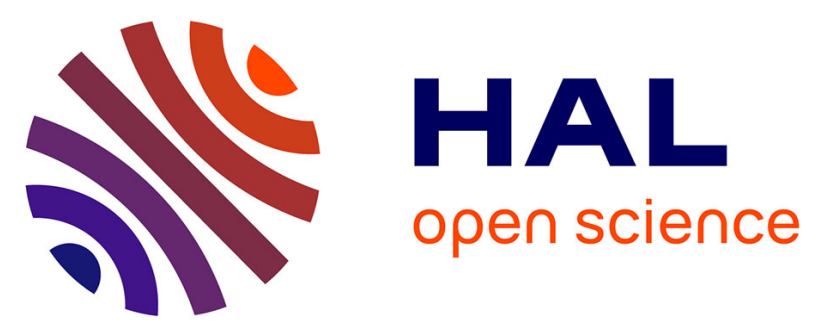

\title{
Development of an autonomous detector for sensing of nerve agents based on functionalized silicon nanowire field-effect transistors
}

\author{
Simon Clavaguera, Nicolas Raoul, Alexandre Carella, Michael Delalande, \\ Caroline Celle, Jean-Pierre Simonato
}

\section{To cite this version:}

Simon Clavaguera, Nicolas Raoul, Alexandre Carella, Michael Delalande, Caroline Celle, et al.. Development of an autonomous detector for sensing of nerve agents based on functionalized silicon nanowire field-effect transistors. Talanta, 2011, 85, pp.2542-2545. 10.1016/j.talanta.2011.08.012 . cea-01344114

\section{HAL Id: cea-01344114 https://hal-cea.archives-ouvertes.fr/cea-01344114}

Submitted on 11 Jul 2016

HAL is a multi-disciplinary open access archive for the deposit and dissemination of scientific research documents, whether they are published or not. The documents may come from teaching and research institutions in France or abroad, or from public or private research centers.
L'archive ouverte pluridisciplinaire HAL, est destinée au dépôt et à la diffusion de documents scientifiques de niveau recherche, publiés ou non, émanant des établissements d'enseignement et de recherche français ou étrangers, des laboratoires publics ou privés. 


\title{
Development of an autonomous detector for sensing of nerve agents based on functionalized silicon nanowire field-effect transistors
}

\author{
Simon Clavaguera, Nicolas Raoul, Alexandre Carella*, Michael Delalande, Caroline Celle, \\ Jean-Pierre Simonato*
}

CEA Grenoble/LITEN/DTNM/LCRE, 17 rue des Martyrs, 38054 Grenoble Cedex 9, France

\section{A R T I C L E I N F O}

\section{Article history:}

Received 27 May 2011

Received in revised form 2 August 2011

Accepted 6 August 2011

Available online 12 August 2011

\section{Keywords:}

Field-effect transistor

Nerve agent

Organophosphorus

Sensor

Silicon nanowire

Prototype

\begin{abstract}
A B S T R A C T
The ability to detect minute traces of chemical warfare agents is mandatory both for military forces and homeland security. Various detectors based on different technologies are available but still suffer from serious drawbacks such as false positives. There is still a need for the development of innovative reliable sensors, in particular for organophosphorus nerve agents like Sarin.

We report herein on the fabrication of a portable, battery-operated, microprocessor-based prototype sensor system relying on silicon nanowire field-effect transistors for the detection of nerve agents. A fast, supersensitive and highly selective detection of organophosphorus molecules is reported. The results show also high selectivity in complex mixtures and on contaminated materials.
\end{abstract}

(C) 2011 Elsevier B.V. All rights reserved.

\section{Introduction}

The high lethality and the ease of manufacturing Sarin-like molecules from inexpensive starting materials render nerve agents a weapon of choice for terrorist attacks $[1,2]$. Consequently, counterterrorism activities have been strengthened over the past decade to prevent such potential threat. One goal is to develop reliable, sensitive and specific systems for the detection of organophosphorus molecules in urban areas and battlefields. Several technologies are already used and some others are being developed for the sensing of nerve agents: IMS [3], GC/MS [4], enzymatic assays [5], carbonnanotube based devices [6,7], etc. However the cost, the limited portability, the operational complexity, the false positives and the slow response time make most of these methods inadequate for onsite monitoring devices. As a result, there is still a need for sensitive, compact, low-cost, and low consumption portable devices for nerve agent detection in the field of defence and homeland security.

Silicon nanowire-based field-effect transistors (NW-FETs) are well studied structures [8-12] that give rise to powerful sensors for the detection of chemical species in air [13-16]. For NW sensors operated as FETs, the sensing mechanism is the field-gating effect of charged molecules on the carrier conduction inside the NW $[17,18]$.

\footnotetext{
* Corresponding authors.

E-mail addresses: alexandre.carella@cea.fr (A. Carella), jean-pierre.simonato@cea.fr (J.-P.Simonato).
}

We report herein the development and the appraisal of a supersensitive and fast reacting portable hybrid detector of nerve agents based on electrical transduction of a chemical reaction occurring on the surface of a functionalized silicon nanowire field-effect transistor (SiNW-FET). This device bearing the adequate functionality on the SiNW-FET, a power source and a microcontroller for data processing was fabricated to investigate its relevance for the detection of nerve agents in complex environments. The exceptional performances of the SiNW devices enable the detection of nerve agent simulant with high sensitivity and excellent selectivity.

\section{Materials and methods}

\subsection{Sensitive material fabrication}

A series of molecular sensors was described elsewhere in which the reaction of a primary alcohol with an organophosphorus compound (OP) initiates an intramolecular cyclization to generate a quaternary ammonium species which can be identified (Scheme 1) $[14,19]$. In order to investigate the influence of the charge generation on the electrical properties of a SiNW-FET, an anchoring unit may be used to localize the molecular receptor onto the nanowire. For instance, an ethynyl anchoring group was used to perform covalent grafting of the molecular receptor on the $\mathrm{Si}-\mathrm{H}$ surface by hydrosilylation.

Compound 1 was synthesized in four steps starting from the Kemp's triacid with an overall yield of $40 \%$ accordingly to the 

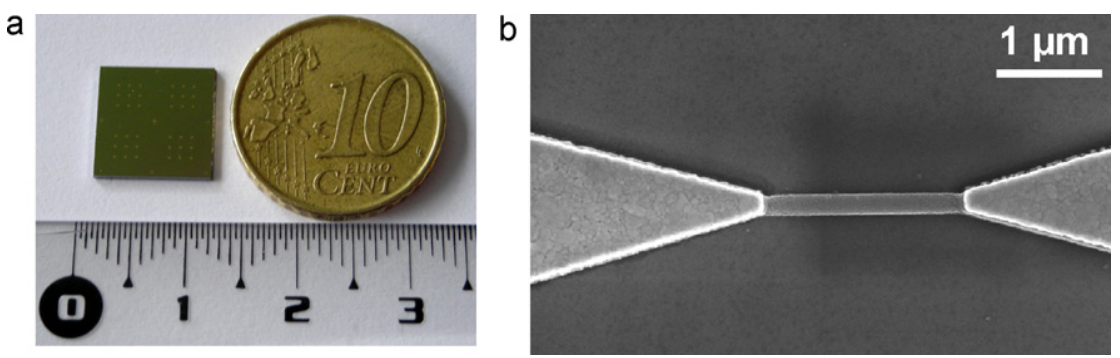

Fig. 1. (a) Image of a chip bearing 36 SiNW-FETs and (b) MEB image of a single SiNW-FET (70 nm thick, $200 \mathrm{~nm}$ wide and $2 \mu \mathrm{m}$ long).

synthetic procedure published elsewhere. FTIR, ${ }^{1} \mathrm{H}$ and ${ }^{13} \mathrm{C}$ NMR, and mass spectrometry spectra were in agreement with literature data [14].

\subsection{Field-effect transistor fabrication/portable hybrid detector fabrication/sensor architecture}

The SiNW-FETs were fabricated from $p$-doped $\left(10^{15} \mathrm{~B}\right.$ atom $/ \mathrm{cm}^{3}$ ) silicon on insulator (SOI) wafers (Fig. 1). SiNW-FETs of $70 \mathrm{~nm}$ thickness with different lengths and widths $(4 \mu \mathrm{m} \times 4 \mu \mathrm{m} ; 4 \mu \mathrm{m} \times 1 \mu \mathrm{m} ; 2 \mu \mathrm{m} \times 1 \mu \mathrm{m}$ and $2 \mu \mathrm{m} \times 0.2 \mu \mathrm{m})$ were obtained by e-beam lithography and dry reactive ion etching steps. The thickness of the $\mathrm{SiO}_{2}$ gate dielectric was $140 \mathrm{~nm}$. $\mathrm{Ti} / \mathrm{Au}(10 / 100 \mathrm{~nm})$ source and drain contacts were achieved by using e-beam lithography and lift-off process. The Si degenerated substrate was used as back gate electrode.

The semiconducting part of the sensor was functionalized via formation of a covalent grafting through thermal hydrosilylation of 1 onto HF-pretreated substrate in refluxing mesitylene for $2 \mathrm{~h}$. We chose to dissociate the electronic part of the device from the sensing element. Thus the transistor chip is connected onto a pluggable plastic card by gold wire bonding for source and drain electrodes and with silver paste deposited onto the back gate electrode (see Fig. 2). Then the sensing card bearing the transistor can be connected to the electronic part of the device through three electrically active pins.

The drain-source and gate-source voltages, respectively $V_{\mathrm{DS}}$ and $V_{\mathrm{GS}}$, are applied while the drain-source current is measured as a function of time (Fig. 3).

The prototype can be divided into three main parts: a microcontroller, a functionalized SiNW-FET acting as the transductor, and digital-analog converters with current-to-voltage circuits

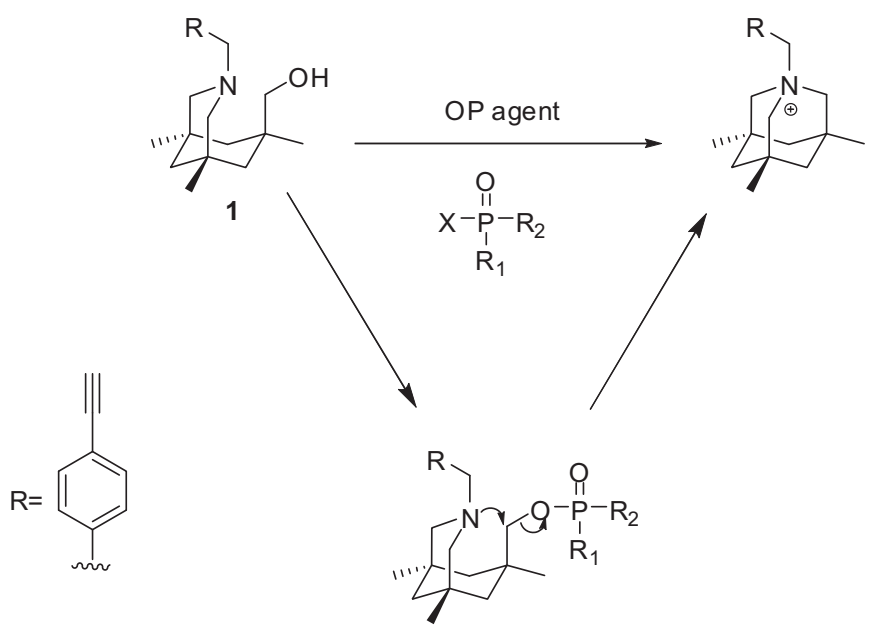

Scheme 1. Reactivity of the molecular receptor $\mathbf{1}$ towards OPs. R is an anchoring group used to graft the molecule on a specific surface.

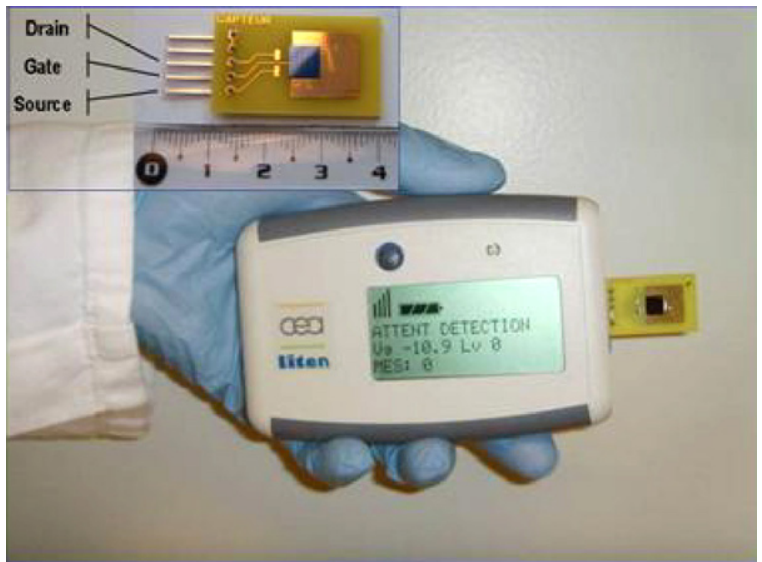

Fig. 2. Picture of the device. Insert shows the field effect transistor wire bonded on a card with the three connectors.

interfacing the FET with the microprocessor. The ultra low-power mixed signal microcontroller from Texas Instruments was installed on the printed circuit board equipped with a digital-to-analog converter and a logarithmic amplifier able to measure very low current over a range of six decades. The drain-source current $I_{\mathrm{DS}}$ is the signal processed by the microcontroller, and the sensor output is proportional to $I_{\mathrm{DS}}$. The board was equipped with a DC/DC converter $( \pm 15 \mathrm{~V})$ that operated from a $9 \mathrm{~V}$ battery, and three security alert elements: a LCD text display, a buzzer and a two-color LED.

\subsection{Sensor operation/test description}

A sampling cycle begins by a calibration step which consists in swipping drain-source current versus gate voltage of the ambipolar transistor, in air, at a constant bias voltage $V_{\mathrm{DS}}=-1 \mathrm{~V}$. Once the transfer curve is acquired, the minimum value of the off-current is identified with the corresponding gate voltage. This particular value of the gate voltage called $V_{0}$ is then applied to monitor the drain-source current as a function of time. It has been shown in previous work that upon reaction with OPs the $V_{0}$ potential of

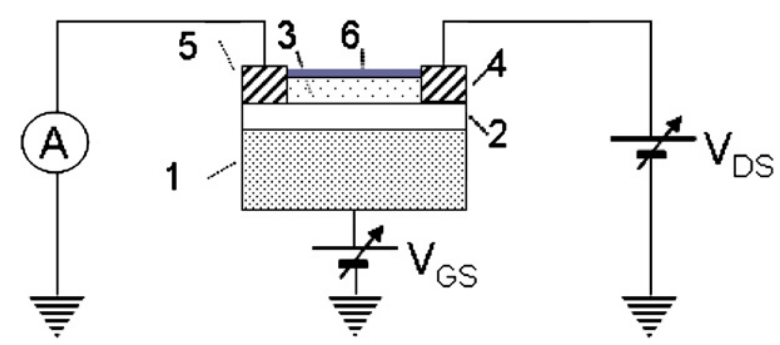

Fig. 3. Scheme of the field-effect transistor based sensor. (1) Highly doped silicon back gate electrode, (2) $\mathrm{SiO}_{2}$ dielectric, (3) $\mathrm{Si}$ semiconducting channel, (4) drain electrode, (5) source electrode, (6) monolayer of grafted receptors. 


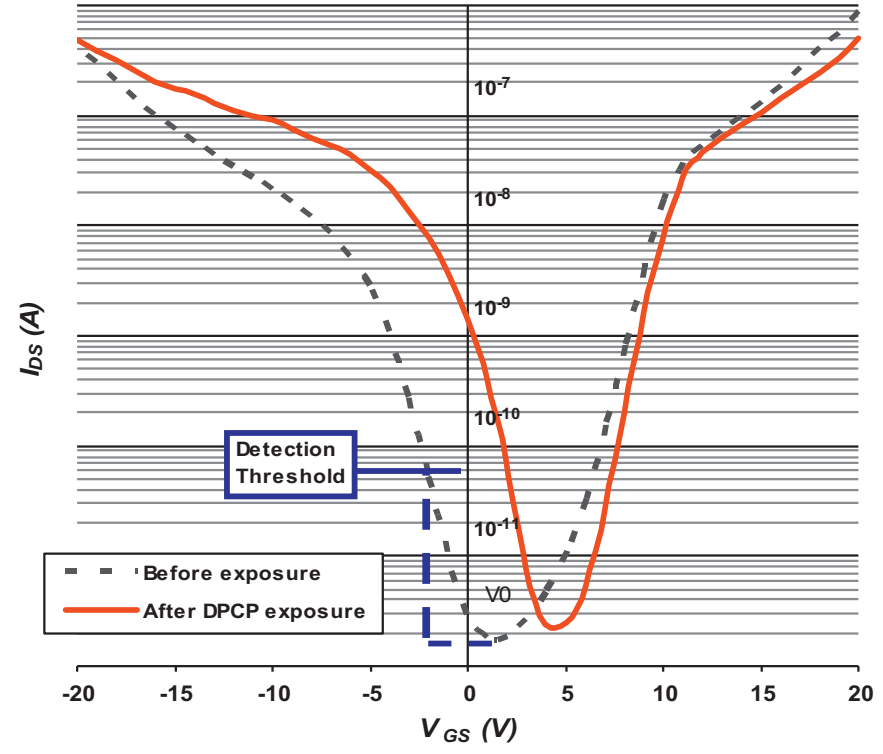

Fig. 4. Functionalized $\mathrm{SiNW}-\mathrm{FET}, I_{\mathrm{DS}}-V_{\mathrm{GS}}$ curves at $V_{\mathrm{DS}}=-1 \mathrm{~V}$ before (red solid line) and after DPCP exposure (black dotted line). (For interpretation of the references to color in this figure legend, the reader is referred to the web version of the article.)

functionalized FET is clearly shifted to more positive gate voltages with an average variation $\Delta V_{0}$ of $(7.3 \pm 3.5) \mathrm{V}$ [14]. As a consequence, the detection threshold is the $I_{\mathrm{DS}}$ value measured during the calibration process for $V_{\mathrm{GS}}=\left[V_{0}-3 \mathrm{~V}\right]$ (i.e. $-2.0 \mathrm{~V}$ in Fig. 4). The alarm is triggered when the drain-source current reaches the predetermined detection threshold (i.e. $\sim 7 \times 10^{-11}$ at $-2.0 \mathrm{~V}$ in Fig. 4).

The sensitive area of the FET is then fed by air that may contain analytes. When the air holds organophosphorus compounds like diphenyldichlorophosphate (DPCP), a good simulant of Sarin, then $I_{\mathrm{DS}}$ monitored by the device raises. If an increase in drain-source current is detected and if $I_{\mathrm{DS}}$ exceeds the previously determined threshold value, then the operator is warned against the possible presence of organophosphorus agents. The alarm status is displayed on the LCD readout along with a blinking LED, and the buzzer set off. A computational algorithm allows the use of a low-power and low-cost microcontroller for data acquisition and analysis. The general testing procedure in the present study was first to acquire an $I_{\mathrm{DS}}-V_{\mathrm{GS}}$ sweep at a constant bias voltage $\left(V_{\mathrm{DS}}=-1 \mathrm{~V}\right)$. Then, after stabilization for $30 \mathrm{~s}$ in air while monitoring continuously $I_{D S}$ at constant bias voltages $\left(V_{\mathrm{DS}}=-1 \mathrm{~V} ; V_{\mathrm{GS}}=V_{0}\right)$, the sensor is exposed to analytes for $10 \mathrm{~s}$. The sensor output, which is proportional to $I_{\mathrm{DS}}$ was processed and analyzed using Eq. (1), to give the so-called sensor response. $I_{\mathrm{DS}}^{0}$ is the drain source current before exposure while $I_{\mathrm{DS}}^{10 \mathrm{~s}}$ is the drain-source current after a $10 \mathrm{~s}$ exposure to analyte vapors.

Sensor response $=\frac{\left|I_{\mathrm{DS}}^{0}-I_{\mathrm{DS}}^{10 \mathrm{~s}}\right|}{I_{\mathrm{DS}}^{0}}$

\section{Results and discussion}

\subsection{Experiments with OP simulants}

The transfer characteristics of the functionalized SiNW-FET measured with an Agilent 4155C Semiconductor Analyzer before and after exposure to vapors of DPCP is depicted in Fig. 4. This curve shows a clear shift to more positive gate voltages of the transfer curve when the transistor is exposed to DPCP vapors. When such an experiment is realized with the portable hybrid detector typically in ambient air at $20^{\circ} \mathrm{C}$ and $45 \%$ relative humidity, a steep increase
Table 1

Values of vapor pressures of tested analytes at $20^{\circ} \mathrm{C}$ unless otherwise indicated.

\begin{tabular}{rll}
\hline Entry & Compound & Vapor pressure (ppmv) \\
\hline 1 & Pentane & 550,000 \\
2 & Cyclohexane & 100,000 \\
3 & Toluene & 30,000 \\
4 & Dichloromethane & 460,000 \\
5 & Acetone & 240,000 \\
6 & Diethyl ether & 580,000 \\
7 & Ethyl acetate & 96,000 \\
8 & N-methyl pyrrolidone & $430\left(25^{\circ} \mathrm{C}\right)$ \\
9 & Tetrahydrofuran & 190,000 \\
10 & Ethanol & 58,000 \\
11 & Iso-propanol & 43,000 \\
12 & Pyridine & 24,000 \\
13 & Propionic acid & $4300\left(27.6{ }^{\circ} \mathrm{C}\right)$ \\
14 & Water (100\% relative humidity) & $\mathrm{N} / \mathrm{A}$ \\
15 & Hydrogen peroxide 30\% in water & $\mathrm{N} / \mathrm{A}$ \\
16 & Bleach/sodium hypochlorite 5\% in water & $\mathrm{N} / \mathrm{A}$ \\
17 & Dimethylmethylphosphonate (DMMP) & $1100\left(25^{\circ} \mathrm{C}\right)$ \\
18 & Diesel exhaust gases & $\mathrm{N} / \mathrm{A}$ \\
19 & Bis-dichlorophenylchlorophosphate & $\mathrm{N} / \mathrm{A}$ \\
20 & Diphenylchlorophosphate (DPCP) & $0.5-0.8$ \\
\hline
\end{tabular}

of the output signal (i.e. proportional to drain-source current) is recorded. It should be noted that the sensor works in a cumulative way. Indeed, the reaction between the grafted receptors and the reactive molecules is irreversible, thus $V_{0}$ shift can be affected both by the concentration of analyte and time exposure. The increase for a 10 s exposure to vapors of DPCP ( $500 \mathrm{ppb})$ gives a sensor response of 78 according to Eq. (1). It has to be noted that when exposed to dry air or air with various relative humidity contents (in the range $0-90 \%$ ), the signal was found to be very stable. We did not observe neither increase nor decrease of the output signal (Table 1 ).

We also used a solid simulant named bisdichlorophenylchlorophosphate which exhibits the same chemical reactivity than OPs and DPCP. To our knowledge, the vapor pressure of this compound has never been reported. However with regard to its known physical properties (melting point $51-56^{\circ} \mathrm{C}$ ), it seems reasonable to assume that very low content of molecules are present in the gas phase (probably few ppb or even lower, and certainly much less than for DPCP). Nevertheless the sensor gives very satisfactory results and actually detects traces of such material (see Fig. 5).

\subsection{Experiments with DMMP}

Diphenylchlorophosphate (DPCP) which is the main simulant used in this study, appears as a good mimic for warfare agents like Sarin or Soman since it has both good structural and chemical reactivity analogies with organophosphorus agents. Dimethylmethylphosphonate (DMMP) is often used as OP simulant. This molecule is clearly a good structural analog to OPs but its chemical

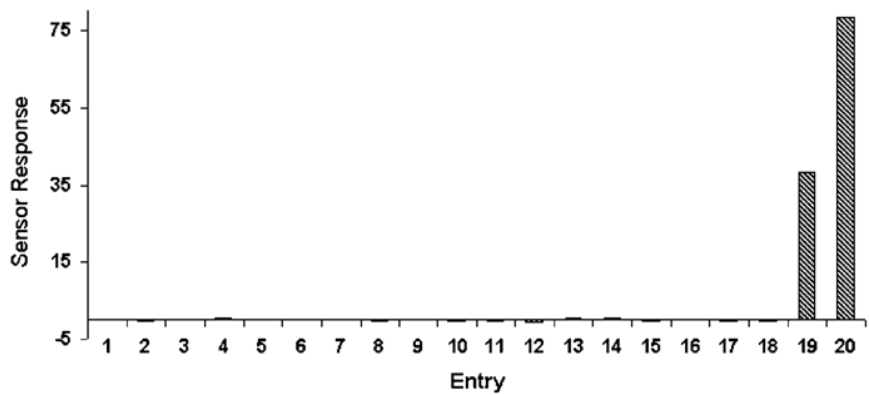

Fig. 5. Sensor response calculated from Eq. (1) for a $10 \mathrm{~s}$ exposure at $20^{\circ} \mathrm{C}$ to several analytes. The analyte names and their vapor pressures are reported in Table 1. 
reactivity does not mimic well the electrophilic behaviour of real nerve agents (methoxy group is a poor nucleofuge). Moreover, due to the fact that this molecule is widely used as a flame retardant, plasticizer, antistatic agent or additive for gasoline, it can compete with the detection of nerve agents in complex environments. In the present study, it is remarkable that the prototype is able to detect very quickly and with an extreme sensitivity DPCP, and does not respond to a structural analog that does not present a similar reactivity to nerve agents like DMMP (Fig. 5).

\subsection{Tests with interferents}

Fig. 5 shows the sensor response for several analytes that could interfere with the sensor operation. No significant effect was observed when the detector was exposed to high concentrations of organic solvents and other domestic volatile compounds. The selectivity of the sensor was thus excellent even with complex atmospheres such as vapors of perfumes (e.g. Hugo Man ${ }^{\circledR}$ perfume, Faconnable ${ }^{\circledR}$ perfume, Soupline ${ }^{\circledR}$ softener) or diesel exhaust gases (entry 18).

\subsection{Demonstration in a relevant environment}

We point out that the sensor is able to detect the presence of DPCP in various environments, representative of real conditions. No positive response was observed when the detector was exposed to cotton cloth, paper or soil particles polluted with solvents, but the sensor set off alarm when exposed to DPCP-tainted cloths, DPCPtainted paper or DPCP-polluted soil (1\%, w/w DPCP in sand). The sensor was also exposed for $10 \mathrm{~s}$ to various mixtures composed of vapors of organic solvents and at times DPCP. The alarm was triggered only when the Sarin simulant was present.

\section{Conclusion}

In conclusion, the present study describes the fabrication of a portable, battery-operated, microprocessor-based prototype sensor system based on SiNW-FET for detection of a nerve agent simulants. An extremely rapid, sensitive and highly selective detection of a Sarin-like molecule is reported. Moreover, our results shows that DPCP can be distinguish among other related compounds, in complex mixtures or on contaminated materials. We have now developed more sensitive devices [18] that will be integrated in the same prototype, which should lead to a further increase in performances. To our knowledge, this approach represents the first fully integrated portable device for the detection of Sarin-like molecules based on nanotechnologies.

\section{Acknowledgement}

We thank Dr. Stéphane Lenfant and Dr. Dominique Vuillaume for the fabrication of SiNW-FET and for helpful discussions. This work was supported in part by the project CAMIGAZ ANR-10-CSOSG-003.

\section{References}

[1] J.A. Romano, B.J. Lukey, H. Salem, Chemical Warfare Agents: Chemistry, Pharmacology, Toxicology, and Therapeutics, 2nd ed., CRC Press Inc., Boca Raton, FL, 2007.

[2] A.T. Tu, Toxin Rev. 26 (2007) 231-274.

[3] M.A. Makinen, O.A. Anttalainen, M.E.T. Sillanpaaa, Anal. Chem. 82 (2010) 9594-9600.

[4] W.E. Steiner, S.J. Klopsch, W.A. English, B.H. Clowers, H.H. Hill, Anal. Chem. 77 (2005) 4792-4799.

[5] M. Pohanka, J.Z. Karasova, K. Kuca, J. Pikula, O. Holas, J. Korabecny, J. Cabal, Talanta 81 (2010) 621-624.

[6] K.Cattanach, R.D. Kulkarni, M. Kozlov, S.K. Manohar, Nanotechnology 17 (2006) 4123-4128.

[7] M. Delalande, S. Clavaguera, M. Toure, A. Carella, S. Lenfant, D. Deresmes, D. Vuillaume, J.-P. Simonato, Chem. Commun. 47 (2011) 6048-6050.

[8] Y. Cui, Z. Zhong, D. Wang, W.U. Wang, C.M. Lieber, Nano Lett. 3 (2003) $149-152$

[9] N.S. Ramgir, Y. Yang, M. Zacharias, Small 6 (2010) 1705-1722.

[10] C. Celle, A. Carella, D. Mariolle, N. Chevalier, E. Rouviere, J.P. Simonato, Nanoscale 2 (2010) 677-680.

[11] M.W. Shao, D.D.D. Ma, S.T. Lee, Eur. J. Inorg. Chem. 27 (2010) 4264-4278.

[12] C.M. Lieber, Z.L. Wang, MRS Bull. 32 (2007) 99-104.

[13] Y. Engel, R. Elnathan, A. Pevzner, G. Davidi, E. Flaxer, F. Patolsky, Angew. Chem. Int. Ed. 49 (2010) 6830-6835.

[14] S. Clavaguera, A. Carella, L. Caillier, C. Celle, J. Pecaut, S. Lenfant, D. Vuillaume, J.P. Simonato, Angew. Chem. Int. Ed. 49 (2010) 4063-4066.

[15] M.C. McAlpine, H. Ahmad, D. Wang, J.R. Heath, Nat. Mater. 6 (2007) 379.

[16] K. Skucha, Z. Fan, K. Jeon, A. Javey, B. Boser, Sens. Actuators B 145 (2011) 232-238.

[17] Y. Cui, Q.Q. Wei, H.K. Park, C.M. Lieber, Science 293 (2001) 1289-1292.

[18] V. Passi, F. Ravaux, E. Dubois, S. Clavaguera, A. Carella, C. Celle, J.-P. Simonato, L. Silvestri, S. Reggiani, J.-P. Raskin, D. Vuillaume, IEEE Electron Device Lett. 32 (2011) 976-978.

[19] T.J. Dale, J. Rebek, J. Am. Chem. Soc. 128 (2006) 4500-4501. 